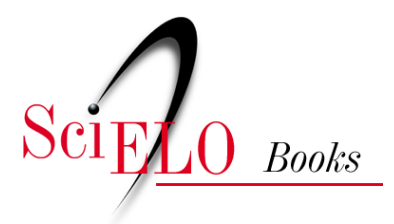

\title{
6. Raça, riqueza e poder
}

\author{
Emerson Ferreira Rocha
}

\section{SciELO Books / SciELO Livros / SciELO Libros}

ROCHA, E.F. Raça, riqueza e poder. In: O negro no mundo dos ricos: um estudo sobre a disparidade racial de riqueza com os dados do Censo 2010 [online]. Brasília: Editora UnB, 2019, pp. 165-191. Pesquisa, inovação \& ousadia series. ISBN: 978-65-5846-052-7. https://doi.org/10.7476/9786558460527.0008.

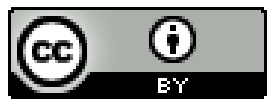

All the contents of this work, except where otherwise noted, is licensed under a Creative Commons Attribution 4.0 International license.

Todo o conteúdo deste trabalho, exceto quando houver ressalva, é publicado sob a licença Creative Commons Atribição 4.0.

Todo el contenido de esta obra, excepto donde se indique lo contrario, está bajo licencia de la licencia Creative Commons Reconocimento 4.0. 


\section{Raça, riqueza e poder}

Até agora foi investigada a relação entre condição racial e riqueza. A disparidade racial na composição do grupo dos ricos foi não apenas descrita, mas também abordada sob o ponto de vista explicativo. Observou-se que essa abordagem explicativa constitui um desafio, já que a variação dos rendimentos entre os mais ricos é pouco sistemática segundo as informações disponíveis no presente estudo. Ainda assim, pôde-se observar o comportamento da mediação educacional da disparidade racial na composição do grupo dos ricos, assim como a desigualdade racial no que tange às condições gerais para a conversão da educação em oportunidades de riqueza.

A relação entre riqueza e poder permitirá que se estude o grupo dos ricos sob outro ângulo: o da formação de elites. É verdade que o grupo dos ricos pode, por si só, ser considerado uma elite com base no seu poderio financeiro, mas se buscará aqui uma definição de “elites” baseada no exercício de controle sobre instituições, o que é mais compatível com as teorias clássicas sobre o tema. Contudo, dificuldades operacionais impõem limitações ao que se pode tratar como "elite” no presente estudo. O termo, por si só, invoca a imagem de altos círculos sociais que concentram uma enorme capacidade de influência sobre o destino da população mais ampla. Além disso, como se trata de grupos com poder de decisão sobre ações afetas ao destino de muitos, é natural que se deseje investigar os processos de formação dessas decisões do ponto de vista individual e biográfico, mas, sobretudo, do ponto de vista coletivo. O que este estudo pretende explorar reside, contudo, naquilo em 
que o tema das elites se aproxima do tema da estratificação social. Não se trata de estudar as decisões das elites, mas diferenças raciais na simultaneidade entre posição de poder e condição de riqueza. Além disso, as posições de poder a serem tratadas não se restringem a altíssimos círculos sociais. Antes, elas abarcam um conjunto de segmentos de elite passíveis de observação com as informações disponíveis no Censo Demográfico.

Na verdade, a definição de “elite” será a mais abrangente possível. Embora amparada na teoria clássica das elites, ela buscará um relativo relaxamento das exigências feitas por esse aporte teórico, de modo a permitir a diferenciação de alguns segmentos de tamanho considerável, algo essencial à análise quantitativa. No contexto de um estudo dedicado à desigualdade racial, essa definição mais abrangente de elite é menos um problema que uma solução. Com efeito, a presença de negros em círculos elevados, como o dos grandes dirigentes corporativos, é tão irrisória que o fechamento do estudo a esses estratos se renderia intratável à análise quantitativa. Sem embargo, é uma característica dos estudos sobre negros nas elites a abordagem segundo uma delimitação abrangente desse grupo, incluindo até mesmo segmentos que, segundo a abordagem de qualquer teoria geral da estratificação, estariam classificados como alguma fração de classe média.

\subsection{Renda e condição de elite}

De maneira geral, define-se “elite” por referência à noção de poder. Elites são grupos que concentram poder no contexto de uma população mais ampla. Isso se aplica mesmo à definição de Pareto, em termos de habilidades diferenciadas. Se, a princípio, a definição do autor se dá por referência à noção de habilidade, e não de poder, há de se considerar que as habilidades, conforme as considera Pareto, são definidas por relação a um campo de atividade socialmente dado, no qual a habilidade se realiza enquanto poder. Poder é a habilidade para a realização de um agir orientado a despeito de restrições socialmente dadas. Em outras palavras, poder é “a chance 
de uma pessoa ou de um grupo realizar a sua própria vontade ainda que contra a resistência de outros participantes da ação” (WEBER, 1982). Observe-se que, nessa definição de poder, há duas componentes básicas: (i) uma vontade a ser realizada e (ii) a capacidade de realizá-la. Sendo assim, a formação de uma elite envolve dois aspectos principais, que todas as teorias da elite abordam em alguma medida.

O primeiro aspecto é o dos processos de formação da vontade. Com relação a esse aspecto, erige-se uma abordagem que investiga como as elites vêm a agir, se é que elas vêm a agir, de tal maneira que se lhes possa interpretar a ação, atribuindo ao grupo, enquanto tal, uma "vontade” ou (aqui há uma plenitude de termos) uma motivação, um objetivo, uma intenção, um interesse. Trata-se de uma investigação sobre a coordenação das ações das elites, coordenação que pode ser baseada no cálculo racional utilitário com referência a interesses convergentes, em um sentimento de comunidade, e, portanto, de solidariedade de classe, em valores compartilhados ou mesmo em acordos não reflexivos. O segundo aspecto, que faz com que as teorias das elites entrem em diálogo, ainda que indireto, com o tema da estratificação social, é o da manutenção do controle sobre recursos que habilitam à imposição da vontade.

Com efeito, a teoria das elites proposta por Pareto, por exemplo, propõe vários enunciados referentes à estratificação social. Pareto observa que não existem exames pelos quais as pessoas seriam distribuídas ao longo das três grandes classes que compõem o seu esquema (i.e., não elite, elite não governante e elite governante). Assim, o que existiriam seriam "rótulos” atribuídos às pessoas, nem sempre de acordo com seus talentos (PARETO, 1963). O rótulo de elite, muito especialmente, estaria amplamente suscetível à herança material e imaterial. Afirma o autor: "Riqueza, família e contatos sociais também colaboram, em tantos outros casos, para a obtenção do rótulo de elite em geral, ou de elite governante, em particular” (Pareto, 1963, p. 1425, tradução nossa). ${ }^{1}$ Mosca também argumenta que as elites,

\footnotetext{
1 "Wealth, family and social connections also help in many other cases to win the label of the elite
} in general, or of the governing elite in particular [...]" 
uma vez constituídas, tendem a monopolizar as chances de aquisição e de desenvolvimento das habilidades associadas ao exercício do poder. $\mathrm{O}$ autor afirma que as elites procuram manter os recursos de poder sob o comando de seus círculos sociais consanguíneos ou próximos. Nas palavras de Mosca, “com a exceção de breves períodos de revolução violenta, qualidades pessoas têm sempre menor importância, no que se refere a obtenção de altas posições sociais, do que nascimento e família” (MOSCA, 1939, p. 123, tradução nossa). ${ }^{2}$ Wright Mills talvez seja o autor mais enfático na proposta de uma sociologia das elites. Se, para Pareto e Mosca, a estratificação social explica a manutenção da condição de elite enquanto a ascensão a essa condição se explicaria mormente pelo mérito, para Mills (1956), os dois movimentos precisam ser explicados a partir de circunstâncias sociais.

Além de colocar a teoria das elites em relação com o tema da estratificação social, a noção de poder estabelece como critério básico de definição da elite o exercício de controle sobre instituições. Embora o segmento de elite não governante em Pareto dispense esse critério, em geral, o foco das teorias recai sobre a capacidade de influenciar ações institucionalizadas, já que as instituições são instâncias de concentração e organização de recursos de poder. Assim, embora o grupo dos ricos, conforme abordado até aqui, possa ser considerado, num sentido mais amplo, uma elite, o objetivo desta seção repousa sobre uma distinção entre riqueza e poder. O grupo dos ricos continua sendo o grupo dos $1 \%$ com maiores rendimentos brutos advindos do trabalho principal. Já as elites são definidas com base em títulos ocupacionais, naquilo que esses podem indicar o exercício de controle sobre instituições. Como há um processo de estratificação social tanto por trás da composição do grupo dos ricos quanto por trás da composição dos segmentos de elite, espera-se que essas duas condições estejam relacionadas.

Mas, se riqueza e poder se relacionam, eles não necessariamente andam juntos. Há aquele que exerce poder e não é rico, assim como há aquele que é rico e

2 “[...] apart from brief periods of violent revolution, personal qualities are always less important, as regards attaining the highest positions in life, than birth and family." 
não exerce poder. Assim, a simultaneidade dessas duas condições configura uma posição especialmente vantajosa. A hipótese central abordada nesta seção é a de que a condição racial afeta as chances dessa simultaneidade, com os negros tendo menores probabilidades de serem, ao mesmo tempo, ricos e membros da elite. Num nível mais específico, testa-se a hipótese de que determinados segmentos de elite oferecem maiores oportunidades para que negros experimentem a condição de elite rica. A próxima seção apresenta os segmentos de elite a serem considerados neste estudo e enuncia as hipóteses acerca da variação da associação entre riqueza e poder para as pessoas negras ao longo desses segmentos.

\subsection{Os segmentos de elite considerados}

O grande desafio operacional deste capítulo está no trato empírico com o conceito de elite, dadas as limitações do que se pode deduzir substantivamente sobre determinada ocupação com base nos títulos ocupacionais. De acordo com as informações disponíveis no Censo Demográfico, três tipos de elite podem ser diferenciados: política, econômica e burocrática. Isso com o segmento econômico se subdividindo entre grandes empregadores, pequenos empregadores e executivos, e com o segmento político se dividindo entre Estado e sociedade civil. Tem-se assim, ao todo, seis segmentos de elite. Antes de avançar na discussão sobre essas definições, é importante notar que o quesito sobre ocupações no questionário do Censo consiste numa pergunta aberta. O instrumento elaborado pelo IBGE para codificar as diversas respostas em um conjunto tratável de categorias ocupacionais é o Código de Ocupações para Pesquisas Domiciliares - COD. Esse instrumento é disponibilizado pelo IBGE, mas não traz maiores esclarecimentos sobre os tipos de ocupações abrangidos por cada título ocupacional e nem sempre os títulos são evidentes a esse respeito. Recorreu-se portanto, às definições do International Standard Classification of Occupations - ISCO - 88, no qual se baseia a codificação utilizada para o Censo Demográfico 2010. Nesse instrumento, encontram-se explicações 
mais detalhadas sobre quais ocupações e atividades determinado título ocupacional abrange e, no que diz respeito aos títulos utilizados para a segmentação de elites aqui proposta, é notável a correspondência entre as categorias do COD e do ISCO.

Considere-se elite econômica aqueles que exercem controle sobre firmas. Obviamente, há, nos mais altos escalões da economia, grupos que acumulam uma grande quantidade de capital e que, agindo por meio de redes que envolvem não apenas outros atores do mundo do empreendimento como também atores estratégicos do setor público, tomam decisões cujo escopo de efeito está, no que compete ao presente estudo, fora de alcance. Deixando, contudo, de lado essa dinâmica de altíssimos círculos que poderiam ser propriamente tratados como "elites de poder" na acepção de Mills (1956), é inegável que as posições de empregador e de chefe-executivo, ambas observáveis no Censo Demográfico, envolvem o controle direto sobre o comportamento de firmas e, portanto, configuram uma condição de elite. Considere-se, primeiramente, os empregadores.

É interessante subdividir esse grupo em pequenos e grandes empregadores, os primeiros sendo aqueles que contratam até cinco pessoas. O critério tem problemas, já que o volume de empregados não mantém correlação clara com o nível de capitalização das firmas, mas é o melhor que se pode fazer com as informações disponíveis no Censo. Essa subdivisão minimiza o problema da grande heterogeneidade de poder existente no conjunto dos empregadores. Existe uma considerável diferença entre os rendimentos médios de pequenos e de grandes empregadores, definidos pelo critério do número de empregados exposto anteriormente. Assumindo que o tamanho das firmas está correlacionado à remuneração dos seus proprietários, a subdivisão proposta realmente distingue um conjunto de proprietários de firmas majoritariamente pequenas e um conjunto de proprietários de firmas majoritariamente maiores.

Os executivos, por sua vez, constituem uma categoria à parte. Sem serem os donos do capital, exercem controle sobre o empreendimento. Muito se discute em torno dessa posição dentro da tradição neomarxista, que, ao propor uma teoria sobre a estrutura de classes como um todo, propõe também, se não uma teoria, detidas 
considerações sobre a elite econômica. A questão é que, para a teoria marxista, a condição de elite econômica se define pela posse do capital e, por isso, o preposto desse dono, por mais que exerça controle real sobre inúmeras decisões, sobretudo calcadas na especialização técnica numa estrutura de empreendimento cada vez mais complexa e diferenciada, ainda não poderia ser tomado enquanto capitalista, encontrando-se, portanto, numa posição contraditória de classe: a de quem exerce funções de capitalista sem, contudo, sê-lo.

Esse tipo de dificuldade teórica já não se coloca ao presente estudo. Define-se elite econômica pelo exercício de controle sobre as empresas. Se o executivo não é o dono da firma, ainda assim ele exerce controle sobre esta. Se ele não é o dono do capital e não tem, portanto, a palavra final sobre onde e como investir, sua palavra é forte e tem um privilegiado poder de influência sobre as decisões de proprietários ou acionistas. Mesmo não estando no último degrau da cadeia decisória, o executivo está, por assim dizer, “quase lá” e, se sua palavra tem influência sobre as grandes decisões, o que se dirá, então, sobre as “pequenas” e contínuas decisões ordinárias, ao nível do pão de cada dia da empresa, decisões que a divisão mesma do trabalho delega a ele.

A elite política inclui os legisladores e os chefes do poder executivo, assim como o alto escalão da administração pública. Esse segmento abarca, portanto, não apenas cargos eletivos, mas também cargos comissionados e de carreira. O que está em questão é, obviamente, o controle sobre ações do Estado. Uma variação da elite política é aquela que não se radica no Estado, mas em organizações civis. O final da década de 1980 marca o início de um acentuado processo de ampliação e de diferenciação do espaço público no Brasil. Observa-se um processo de crescimento, iniciado já na década de 1970, do número de organizações civis (FERNANDES, 1994; LANDIM, 1998). Esse processo constitui base para inúmeros esforços de inovação institucional, como a instituição de diferentes tipos de conselhos, previstos e regulamentados por lei (TATAGIBA, 2002), e as experiências com orçamentos participativos (AVRITZER, 2007; DAGNINO, 2002). 
Também na execução do orçamento público, essas organizações têm assumido um papel importante por meio da descentralização de recursos. Esse método já se firma ao final da década de 1990, com a Lei n 9.790/1999, que institui como instrumento de descentralização o Termo de Parceria entre Poder Público e Organizações Civis de Interesse Público, figura jurídica criada pela mesma lei. Mais adiante, o método é consolidado pelo Decreto $n^{\circ}$ 6.170/2007, que cria o Sistema de Gestão de Convênios e Contratos de Repasse e dita normas para o repasse de recursos da União através de todos os órgão e entidades da administração pública federal para entes de outras esferas federativas e para entidades privadas sem fins lucrativos. Ao mesmo tempo que o terceiro setor ganha densidade institucional e assiste a um crescente influxo de recursos financeiros, pesquisas têm apontado para um alto grau de concentração desses recursos por conjuntos restritos de organizações (LAVALLE, CASTELLO; BICHIR, 2007), o que atesta a existência de processos de formação de elites com suporte nesse ambiente institucional.

Posições de direção na burocracia também são dignas de consideração enquanto segmento de elite. Embora não estejam no topo da cadeia de comando, os burocratas exercem controle sobre decisões operacionais relevantes. Além disso, seu conhecimento privilegiado dos instrumentos de execução, de controle e de estabilização de rotinas tende a torná-los atores relevantes em processos decisórios envolvendo os ciclos de comando mais elevados. Em seu estudo sobre as Elites de Cor, Azevedo (1955) tratou a burocracia como uma das portas de acesso à condição de elite para a população negra. O autor considerou, contudo, apenas a burocracia estatal. No presente estudo, segue-se mais de perto as colocações de Weber (1982), compreendendo-se a burocracia enquanto um mecanismo de racionalização de procedimentos comum tanto ao Estado quanto ao mercado. Considera-se elite burocrática o conjunto de dirigentes, sejam eles funcionários públicos, sejam eles empregados em empresas. A elite burocrática é aquela que não exerce controle decisório direto, mas sim controle operacional sobre instituições nos setores público e privado. 
A revisão bibliográfica apresentada na seção 5.1 aponta para a hipótese de que o Estado seria o espaço mais permeável à ascensão de negros a posições de elite (AZEVEDO, 1955). Assim, espera-se associação mais forte entre riqueza e poder para negros por meio desse segmento. Ainda nas elites políticas, espera-se que a sociedade civil seja um ambiente institucional especialmente permeável à população negra, dados os princípios de democracia participativa e de inclusão social que estão na base do seu processo de formação. Espera-se que o terceiro setor seja um ambiente institucional especialmente permeável a demandas políticas de diversos segmentos sociais. Sendo assim, é pertinente esperar que essa permeabilidade se reverta também na composição dos quadros que ocupam postos de direção nessas instituições. A burocracia também se revela um segmento relativamente mais aberto aos negros. Por outro lado, a revisão aponta para maiores barreiras ao ingresso de negros no âmbito da elite econômica. Observou-se que posições da elite executiva, muito especialmente, são insolventes à população negra.

Finalmente, cabe salientar que, a essa altura, a metodologia utilizada no presente capítulo dispensa apresentações. Tratam-se de regressões logísticas, já amplamente utilizadas aqui. Com essas técnicas, estima-se a probabilidade de que diferentes grupos pertençam a determinado segmento de elite, de maneira condicional à presença entre os $1 \%$ mais ricos. A probabilidade de pessoas ricas de determinado grupo racial comporem determinado segmento de elite será a medida de associação entre riqueza e poder para esse grupo em relação ao respectivo segmento. Utilizando as possibilidades de controle estatístico oferecidas por essa modelagem, testa-se também a hipótese de que os padrões diferenciais de associação entre riqueza e poder se explicam, em alguma medida, pelas desigualdades em termos de áreas de formação.

Os modelos incluem um termo de interação entre condição racial e riqueza. A motivação para isso não são testes formais de ajuste do modelo, mas o fato de que a desigualdade racial varia ao longo da distribuição de renda, atingindo maior nível nos quantis mais altos dessa distribuição. Nas aplicações, o coeficiente desse termo 
de interação não é estatisticamente significativo ao nível de 95\%. Isso, contudo, diz muito pouco, já que a significância estatística dos efeitos de termos de interação em modelos logísticos não é acessada pelo teste de significância do coeficiente associado ao termo (NORTON; WANG; AI, 2004). Como análises preliminares não revelaram variações por estratos geográficos, considera-se a população de todas as regiões. Isso destoa da restrição à população urbana da região Sudeste utilizada na maior parte das aplicações. A motivação para isso é a baixa frequência de pessoas, especialmente negras, em alguns títulos ocupacionais utilizados para a delimitação dos segmentos de elite, sobretudo quando se trata da interseção entre posição de elite e riqueza. $\mathrm{O}$ uso do total da população permitiu que se garantisse um número satisfatório de observações nesses casos.

\subsection{Disparidades raciais na associação entre riqueza e poder}

A condição simultânea de rico e de elite ocorre com frequência considerável. Na população em estudo, cerca de $36 \%$ dos ricos ocupam posições em um dos segmentos de elite aqui definidos, mostrando que uma fração substancial dos ricos ocupa postos de elite. Essa elite rica, por sua vez, representa aproximadamente 7\% da composição total da elite, ou seja, uma porção menor da elite como um todo é também classificada como rica. Isso se explica pelo fato de que a elite é um grupo relativamente grande, o que se deve à definição pouco restritiva aqui adotada. Lembre-se que até mesmo a pequena burguesia foi incluída enquanto um segmento de elite por deter o controle sobre firmas. A elite, como um todo, perfaz $5,8 \%$ da população total.

Os negros são minoria em todos os segmentos de elite considerados. Isso vale para os segmentos como um todo e mais ainda em se tratando das elites ricas. Contudo, a concentração de negros e de brancos ricos entre os segmentos de elite varia bastante. Para cada segmento de elite, considere-se a probabilidade de pertencer a esse segmento condicional à classificação racial e à condição de riqueza. O interesse está 
na razão de probabilidades entre negros e brancos ricos de pertencerem ao respectivo segmento. Uma razão de probabilidades maior que um significa uma concentração de negros. Uma razão menor que um significa uma concentração de pessoas brancas.

Note-se bem: uma razão maior que a unidade não significa que os negros sejam maioria no segmento de elite em questão. Como já mencionado, os negros são minoria em todos os segmentos de elite. O que uma razão de chances maior que a unidade significa é que os negros ricos estão mais concentrados naquele segmento que os brancos ricos. Na presente aplicação, a razão maior que um significa, em geral, que: (i) a proporção de negros naquele segmento de elite rica é maior que a proporção de negros no grupo dos ricos como um todo; e (ii) a proporção de brancos no mesmo segmento de elite rica é menor que sua proporção no grupo dos ricos como um todo. Isso pode acontecer mesmo os negros sendo minoria no respectivo segmento de elite. O Gráfico 6.1 mostra as razões de probabilidade para cada segmento de elite.

Gráfico 6.1: Associação entre riqueza e poder para os negros por segmento de elite.

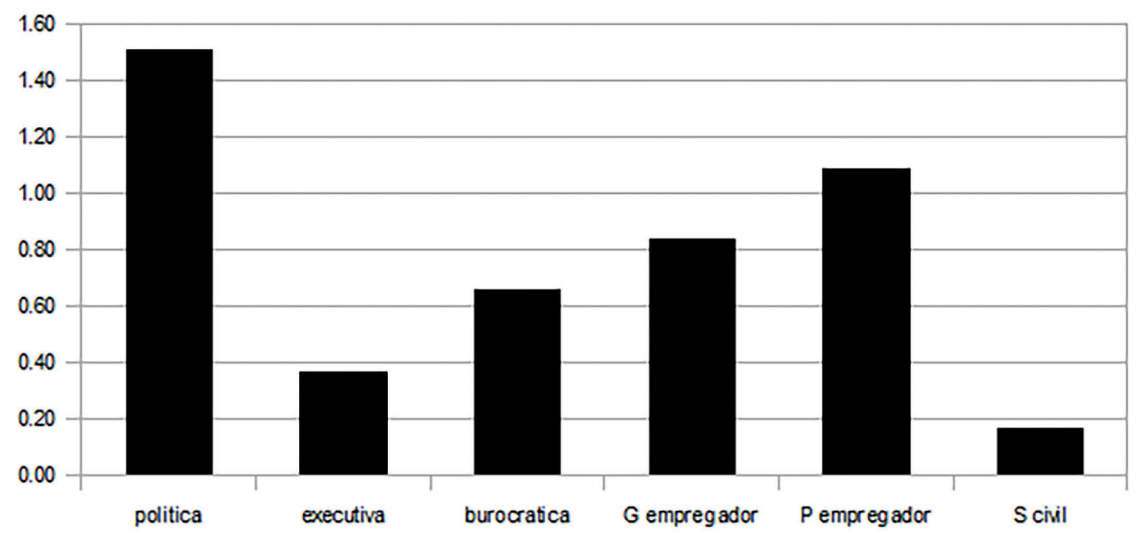

Fonte: IBGE - Censo Demográfico 2010 - Microdados. Elaboração própria.

Nota-se uma variação substantiva na relação entre riqueza e poder entre os grupos raciais. O segmento estatal da elite política aparece como o de maior concentração de negros. Isso está em consonância com o observado por Azevedo (1955), que notou permeabilidade das elites políticas aos negros. Nunca é demais 
lembrar que o resultado reportado aqui não significa prevalência de negros sobre brancos na elite estatal. Pelo contrário, negros são minoria nesse segmento de elite, como em todos os outros. O que se observa é uma conexão mais forte, para as pessoas negras, entre riqueza e poder político por meio de posições na estrutura do Estado.

Essa situação contrasta com a condição de elite política ancorada na sociedade civil, onde a conexão entre riqueza e poder é a mais fraca para os negros. Esse dado é significativo. As organizações da sociedade civil são vistas como suporte para uma experiência radical de democracia. Espera-se que essas constituam canais de participação popular na vida pública. Além disso, espera-se uma prevalência de valores democráticos e inclusivos no seio dessas organizações, o que deveria torná-las especialmente permeáveis à atuação de minorias. Contudo, o que se observa, no que se refere à questão racial, é uma baixa permeabilidade aos negros nas posições mais elevadas. É preciso considerar, contudo, que esse segmento inclui não apenas organizações civis voltadas para políticas sociais, mas também instituições tão díspares como organizações de classe e associações esportivas. É impossível desagregar esse conjunto, já que todos estão reunidos em uma única categorial pelo Código de Ocupações para Pesquisas Domiciliares. De qualquer modo, a disparidade racial observada é muito intensa e, por isso, dificilmente não estaria refletindo uma impermeabilidade realmente em jogo na sociedade civil.

Note-se que, entre os não ricos, a razão de probabilidades para esse segmento não é tão desvantajosa para as pessoas negras, ficando em torno de 0,87, ou seja, bem próxima à igualdade. É só quando se considera a elite rica que se tem a razão de 0,16 exposta no Gráfico 5.1. Em outras palavras, para os não ricos existe, como seria esperado, uma permeabilidade considerável aos negros. O que existe é uma forte impermeabilidade nas posições mais remuneradas. Tem-se observado uma forte concentração de recursos no âmbito do terceiro setor (LAVALLE; CASTELLO; BICHIR, 2007), parece que os negros estão entrando na base desse campo, mas não nas poucas organizações que concentram altas proporções dos recursos. 
Na esfera econômica, os negros ricos aparecem concentrados entre os pequenos empregadores, ou seja, em um grupo com menor poderio. Entre os grandes proprietários, a razão de probabilidades está abaixo da unidade, indicando uma associação entre riqueza e poder mais fraca que aquela existente entre os brancos. A razão de 0,84 está, contudo, relativamente próxima à unidade, indicando que a disparidade racial aí não é tão grande. Para interpretar esse valor, é preciso considerar que o que define o grande empregador, no presente estudo, é um ponto de corte: a contratação de cinco ou mais empregados. Sendo assim, o grupo dos grandes empregadores abarca empresas dos mais variados portes. Tudo leva a crer que o que permite uma relação não tão fraca entre riqueza e poder para os negros através desse segmento de elite é a inclusão de empresas relativamente menores, onde os negros provavelmente se concentram mais.

O segmento da elite executiva revela uma disparidade racial severa, com uma razão de probabilidades de 0,37. Mesmo entre os não ricos, a razão de probabilidades entre negros e brancos de pertencerem a esse segmento de elite se mantém nesse mesmo patamar. Há, portanto, uma forte impermeabilidade desse segmento de elite à população de cor. É interessante notar que esse é muito provavelmente o mais homogêneo dos três segmentos da elite econômica. Enquanto os grupos dos pequenos e dos grandes empregadores comportam firmas de porte muito variado e, portanto, posições com níveis de poder também muito variados, a posição de executivo tende a existir apenas em empresas suficientemente grandes e estruturadas. Em outras palavras, os títulos ocupacionais de diretores e de gerentes-gerais, utilizados aqui para definir os executivos, é um indicador muito mais consistente de uma condição de elite econômica. Isso se nota pelas características da distribuição de renda entre os três segmentos. O nível da renda dos executivos, medido pela média, é maior que o dos pequenos empregadores, muito próximo ao dos grandes empregadores e, ao mesmo tempo, sua dispersão é menor. O coeficiente de dispersão - desvio padrão dividido pela média - da renda dos executivos é de 1,6, contra 2,3 entre os pequenos, e de 2,4 entre os grandes empregadores. Há, portanto, uma 
concentração em níveis de rendimento mais altos, sugerindo que se trata consistentemente de pessoas que trabalham em firmas de porte, nas quais a posição de controle e gerência equivalem ao exercício de um poder considerável.

O segmento dos executivos talvez apresente esse quadro crítico pelas características do acesso a essa posição. Primeiramente, a escolha de pessoas para ocupar tais cargos está sujeita a práticas de discriminação direta. Além disso, a escolha, nesse caso, demanda altos níveis de confiança, e um recurso usual para satisfazer essa demanda é a procura de pessoas por meio de uma rede de contatos de confiança já existente. Assim, a inserção prévia em círculos de elite assume talvez um papel crítico na definição das chances de se ser um executivo, tornando esses cargos muito menos uma via de ascensão e muito mais uma via para a manutenção de posições sociais por grupos afluentes. Isso, fatalmente, prejudica um grupo historicamente excluído, cuja penetração nas elites depende, sobretudo, de vias de ascensão social. Além disso, o capital social, além de explicação concorrente a práticas de discriminação racial direta, constitui um possível meio de manifestação dos próprios efeitos dessa discriminação. As resistências sociais às pessoas negras tendem a obstaculizar a formação de capital social, tornando-o um mecanismo de mediação de desvantagens associadas à condição racial.

É verdade que, diante dos elementos empíricos aqui mobilizados, essa interpretação mantém-se num nível altamente especulativo, já que não se dispõem de informações sobre os processos de contratação dos executivos, repousando as presentes ponderações no conhecimento ordinário de caráter assistemático dado pela experiência de mundo. Não obstante, esses apontamentos são válidos e, talvez, sejam também explicação para a disparidade encontrada no âmbito da sociedade civil. Sem embargo, as organizações civis mais afluentes, aquelas que concentram maiores quantidades de recursos, assumem uma estrutura de administração com caris empresarial. $\mathrm{O}$ acesso à elite rica ancorada na sociedade civil seria, assim como o acesso à elite executiva, bastante fechado. Lembre-se que é exatamente na elite rica da sociedade civil que existe uma drástica disparidade racial, sendo 
essa disparidade mais amena em se tratando da elite não rica. Embora não se possa desagregar a categoria com os dados do Censo, é razoável admitir que a alta renda está relacionada a posições de direção e de gerenciamento nas organizações mais ricas e burocraticamente estruturadas. As barreiras aos negros na sociedade civil estariam, por assim dizer, entre os executivos desse segmento.

Já na burocracia se assiste a um quadro intermediário de disparidade mais moderada, indicada por uma razão de probabilidades na ordem de 0,66. A burocracia não apenas inclui a seleção impessoal por meio de concursos públicos quando se trata do Estado. Também no âmbito do setor privado, a burocracia talvez constitua um nível em que prevalecem processos de seleção, recrutamento e progressão de carreira mais impessoais. Com isso, a permeabilidade ao negro aumenta, embora, no caso do setor privado, em contraste com a via dos concursos públicos, práticas de discriminação racial direta tenham ainda espaço aberto nos processos de seleção. No setor privado, a não interferência da discriminação depende das disposições e da vigilância dos responsáveis pela seleção e pelo recrutamento, diferentemente do que acontece com a maior parte dos concursos públicos, que são “cegos à cor”, a não ser nos casos em que entrevistas compõem o processo de seleção. No setor privado, entrevistas de emprego constituem um procedimento padrão e não são, de maneira alguma, "cegas à cor”.

Estando os diferentes segmentos de elite ancorados em atividades diversas, é de se questionar se essas diferenças raciais no padrão de associação entre riqueza e poder não são mediadas, em alguma medida, por desigualdades educacionais, sobretudo em termos de credenciais. Com efeito, observou-se, no capítulo anterior, que negros e brancos se distribuem desigualmente entre as diferentes áreas de formação e que essa distribuição desigual medeia parte da disparidade racial de riqueza. Algo semelhante pode acontecer nas disparidades raciais na associação entre riqueza e poder. A concentração de negros em determinados segmentos da elite pode ser, em parte, explicada por diferenças educacionais. Determinadas formações poderiam ter maior afinidade com determinados segmentos de elite. 
Por exemplo, a área de formação da administração, comércio e economia com a posição de executivo. Dada essa associação, a distribuição desigual de negros ao longo das áreas de formação responderia, pelo menos em parte, pela maior ou menor concentração de negros em determinado segmento de elite. Essa hipótese pode ser testada inserindo-se os níveis educacionais no modelo utilizado e, então, verificando-se se as razões de probabilidade associando riqueza e poder variam de acordo com as áreas de formação. Em outras palavras, passa-se a comparar negros e brancos com a mesma formação. Assim, para cada segmento de elite, computa-se a razão de probabilidades entre negros e brancos ao longo de todas as áreas de formação. O Gráfico 6.2 mostra o resultado:

Gráfico 6.2: Controle da associação entre riqueza e poder por áreas de formação.

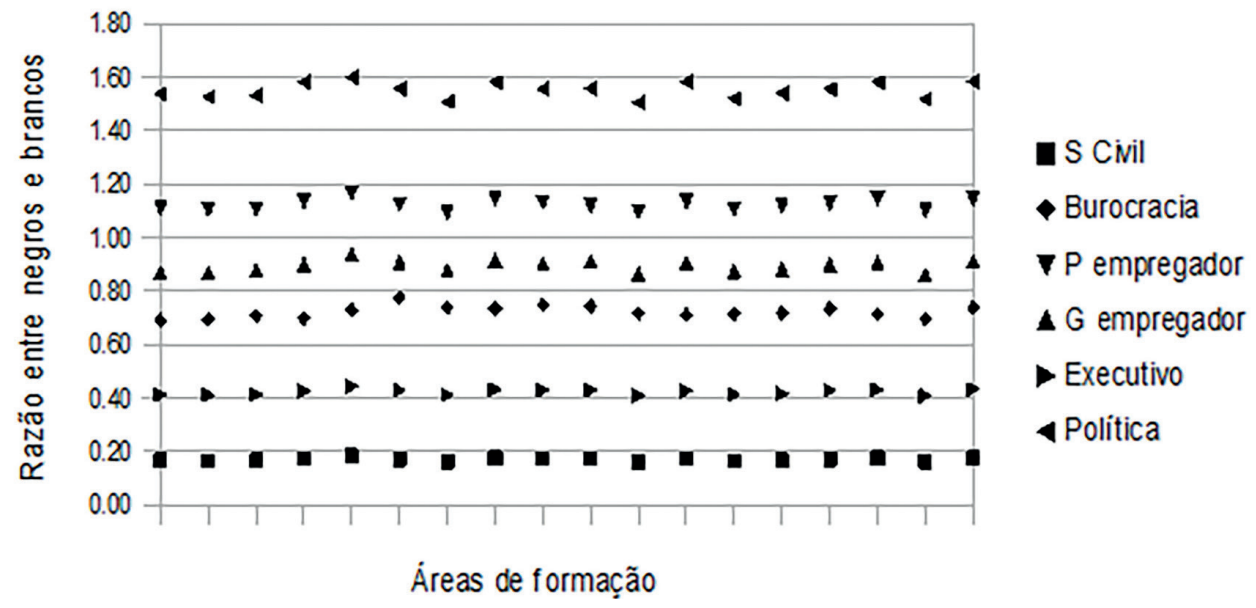

Fonte: IBGE - Censo Demográfico 2010 - Microdados. Elaboração própria.

Como se nota, para todos os segmentos de elite, a razão de probabilidade entre negros e brancos não varia muito ao longo das diferentes áreas de formação, mantendo-se em níveis muito próximos aos obtidos no modelo sem controle por níveis educacionais. Por exemplo, no segmento político, ela se mantém em torno de 1,60 e, no segmento da sociedade civil, próxima a 0,16. Fossem as disparidades 
raciais nos padrões de associação entre riqueza e poder uma função da distribuição desigual por áreas de formação, a disparidade entre negros e brancos dentro de uma mesma área de formação seria substancialmente menor que aquela observada quando não se leva em conta essas áreas. No entanto, pelo contrário, as razões de probabilidade condicionais à área de formação são aproximadamente constantes. O que se nota são ligeiras flutuações que, em nenhum momento, alteram o ordenamento entre os diversos segmentos. Em outras palavras, qualquer que seja a área de formação considerada, as diferenças raciais na associação entre riqueza e poder ao longo dos segmentos de elite mantêm o mesmo padrão. Existem, portanto, mecanismos subjacentes, que não a desigualdade educacional, respondendo por essas diferenças.

Esses mecanismos podem operar tanto pelo fechamento do acesso a círculos sociais de elite quanto pela abertura dos processos de ingresso à ação da discriminação racial direta, sendo que, provavelmente, essas duas coisas contam. Quanto ao primeiro aspecto, já foi observado, na seção anterior, que as teorias clássicas das elites estão de acordo ao apontarem para a tendência das elites em circunscreverem o acesso às suas posições aos membros da própria comunidade. Essas comunidades não precisam constituir círculos sociais de convívio consolidados num dado momento. Antes, elas estão em constante processo de formação mediante proximidades e distâncias estabelecidas pela disposição geral da estratificação social. A esse respeito, Bourdieu (1984) mostra como a formação de grupos de status ancorados em posições de classe (Weber já sugeria que nas condições postas pela ordem econômica e social moderna as posições de status tenderiam a se ancorar materialmente em posições de classe) dita afinidades sociais não apenas em termos de interesses pecuniários compartilhados, mas em termos de gostos ou, de maneira geral, de estilização da vida, configurando, assim, “comunidades” em potencial, ou melhor, um potencial para a formação de comunidades. Esse processo de formação de capital social interno a grupos de status operaria um fechamento do acesso a pessoas negras. 
A discriminação racial, por sua vez, tem o potencial de afetar diretamente o acesso tanto quanto este se baseie em interações abertas à prática discriminatória. Além disso, ela também pode afetar o acesso à elite de maneira indireta, interagindo com o processo de formação de capital descrito anteriormente. Na medida em que o preconceito interfere na formação de status com base na posição de classe e em méritos individuais, ele prejudica o acesso do negro aos círculos sociais em que se circunscrevem boa parte das oportunidades para ocupar determinados postos de elite.

Em conclusão, os negros estão claramente concentrados nos segmentos de elite menos poderosos na esfera econômica. Isso se revela pela concentração na pequena burguesia e pela fraquíssima associação entre riqueza e poder para os negros através do segmento dos executivos. Lembre-se de que a disparidade racial mais moderada entre os grandes empregadores deve ser vista com muito cuidado, pois se trata de um grupo muito heterogêneo, tudo levando a crer que os negros estão concentrados entre os menores dentre os grandes empregadores.

Na esfera política, assiste-se a duas tendências opostas. Por um lado, a elite política ancorada no Estado mostra menor disparidade racial. É aí que se observa a mais forte associação entre riqueza e poder para as pessoas negras. Já na sociedade civil, observa-se o contrário. Ali, a associação entre riqueza e poder é a mais fraca para os negros, mais fraca até que entre os executivos. Pelo menos no que diz respeito à questão racial, portanto, a formação de elites ricas no âmbito da sociedade civil parece ser menos democrática do que no âmbito do próprio Estado. A burocracia fica numa posição intermediária, com uma disparidade racial mais moderada. É importante lembrar que o poder de que dispõem os burocratas é relativamente menor, pois não se trata de um poder de comando direto, mas apenas um poder indireto, derivado do controle operacional sobre procedimentos. Sendo assim, a associação não tão fraca entre riqueza e poder para os negros nesse segmento de elite manifesta, antes de tudo, a tendência geral de baixa associação entre riqueza e poder para pessoas de cor. 


\subsection{Associação entre riqueza e poder para as mulheres negras}

Tanto a condição racial quanto a condição de gênero relacionam-se não apenas às oportunidades de riqueza, mas também às oportunidades de exercício de poder. De maneira geral, ser negro implica desvantagens, e ser mulher, também. Algo que coloca a mulher negra, mais uma vez, em situação crítica. Com efeito, tanto homens quanto mulheres são minoria entre os ricos, assim como entre todos os segmentos de elite aqui considerados. O que está em questão, contudo, não é essa condição minoritária. O que se está explorando é algo diferente: as diferenças na associação entre riqueza e poder. Como já foi visto até aqui, mesmo os negros sendo minoria em qualquer dos segmentos de elite, é possível identificar determinados segmentos para os quais a associação entre riqueza e poder é mais forte para os negros do que para os brancos. Não é que os negros sejam maioria ali. Na verdade, o máximo que eles alcançam entre os diversos segmentos da elite rica é a proporção de $22 \%$ no segmento estatal. Em todos os outros, sua proporção é ainda menor. Mas, se apenas cerca de $16 \%$ dos ricos são negros, o fato desse grupo racial representar cerca de $22 \%$ da elite rica estatal indica uma tendência à concentração dos negros ricos nesse segmento. São exatamente essas relações que estão sendo chamadas de associação entre riqueza e poder e são elas que a modelagem logística identifica para gerar as probabilidades com as quais se tem trabalhado neste capítulo. O mesmo será feito agora considerando também o sexo das pessoas.

A grande questão posta é como sexo e condição racial interagem no condicionamento da associação entre riqueza e poder, determinando a associação entre riqueza e poder para a mulher negra. Utilizando a mesma modelagem da seção anterior, obtém-se agora probabilidades associando riqueza e poder para quatro grupos: homens brancos, mulheres brancas, homens negros e mulheres negras. O que se computa é a probabilidade de pertencer a determinado segmento de elite condicional à riqueza, à raça e ao sexo das pessoas. Os resultados para o segmento estatal da elite são mostrados no Gráfico 5.3. Os gráficos que vêm na sequência 
apresentam o mesmo resultado para os outros segmentos. As escalas no eixo vertical não são as mesmas. Isso porque alguns segmentos, como o da sociedade civil, são muito pequenos, com probabilidades ínfimas de pertencimento em termos absolutos. Com isso, as escalas se dilatam ou se contraem para que sejam visíveis as desigualdades relativas entre as probabilidades associadas aos grupos. Isso quer dizer que o leitor deve evitar uma comparação entre os gráficos com base na inspeção visual, atendo-se à comparação entre as barras dentro de um mesmo gráfico.

Gráfico 6.3: Associação entre riqueza e poder por raça e sexo: segmento estatal.

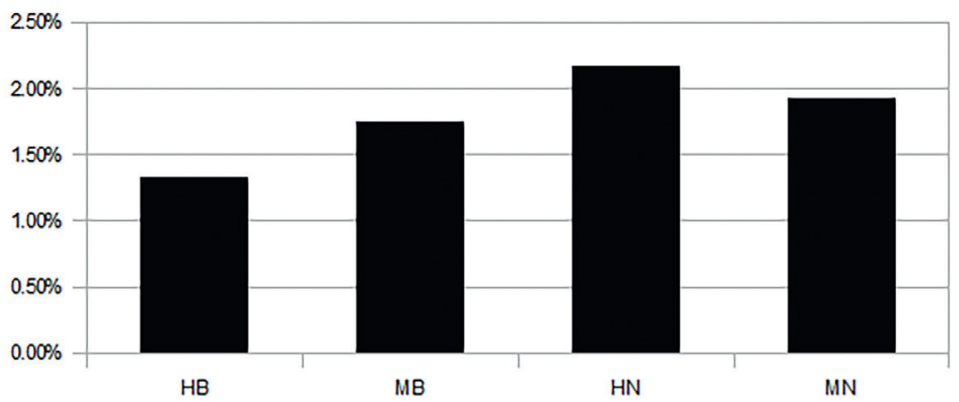

Fonte: IBGE - Censo Demográfico 2010 - Microdados. Elaboração própria.

Nota-se que a hierarquia das probabilidades aponta para uma saliência das diferenças por condição racial com uma diferenciação por sexo secundária, que se inverte entre os grupos raciais. Pessoas negras, homens ou mulheres, estão mais concentradas nesse segmento de elite. Por outro lado, os homens negros estão mais concentrados que as mulheres negras. Relação que se inverte entre os brancos, estando as mulheres, nesse caso, mais concentradas que os homens. Existe uma permeabilidade racial desse segmento de elite que é, no entanto, menos eficaz em se tratando da mulher negra. Ao mesmo tempo, para as mulheres brancas, o segmento estatal da elite está relativamente mais aberto. Há, assim, uma permeabilidade desse segmento aos grupos em desvantagem, mas, para as mulheres negras, essa permeabilidade se restringe. Entre os executivos o quadro é diferente, como mostra o Gráfico 6.4. 
Gráfico 6.4: Associação entre riqueza e poder por raça e sexo: segmento executivo.

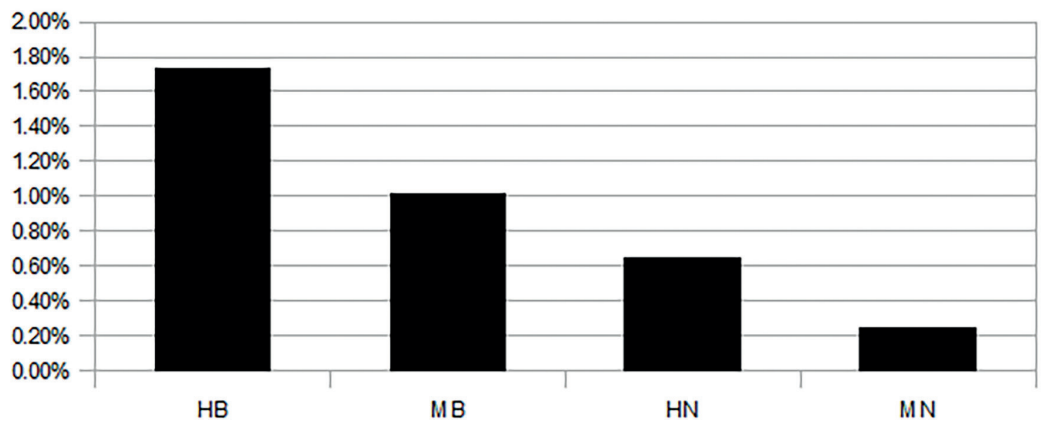

Fonte: IBGE - Censo Demográfico 2010 - Microdados. Elaboração própria.

Mais uma vez, o crivo racial se sobrepõe às diferenças por gênero na associação entre riqueza e poder. Pessoas negras estão menos concentradas nesse segmento. Por outro lado, as diferenças por gênero são agora as mesmas ao longo dos grupos raciais: mulheres brancas menos concentradas que os homens brancos e mulheres negras menos concentradas que homens negros. O segmento executivo revela, assim, uma hierarquia bem clara conjugando raça e gênero. Maior permeabilidade a pessoas brancas com permeabilidade menor à mulher branca especificamente. A permeabilidade à mulher branca ainda é maior, contudo, que ao homem negro. A mulher negra, por sua vez, está no último degrau da escada. Já entre os grandes empregadores, o quadro é outro, como mostra o Gráfico 6.5:

Gráfico 6.5: Associação entre riqueza e poder por raça e sexo: grandes empregadores.

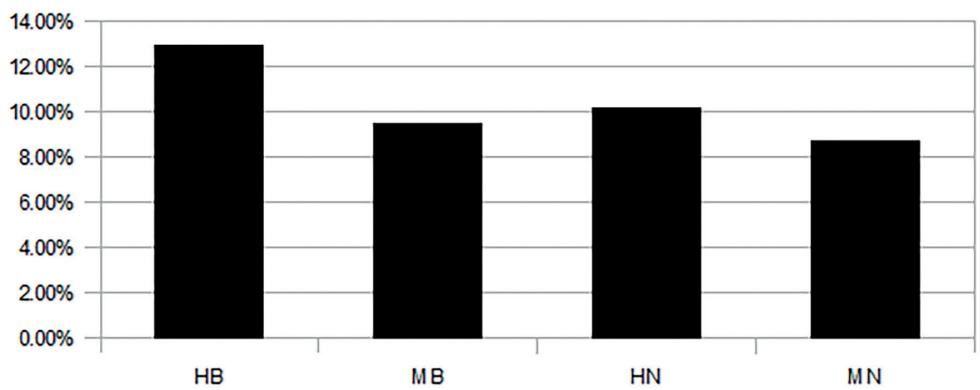

Fonte: IBGE - Censo Demográfico 2010 - Microdados. Elaboração própria. 
Nesse caso, as diferenças por sexo são mais salientes. Os homens, de maneira geral, estão mais concentrados entre os grandes empregadores. Os homens negros estão abaixo dos homens brancos, e as mulheres brancas, abaixo dos homens negros. A mulher negra, mais uma vez, aparece em último lugar. Entre grandes proprietários e executivos, existe, portanto, uma inversão interessante na ordem dos critérios de estratificação. A condição de proprietário é, sobretudo, uma via de associação entre riqueza e poder para os homens. É importante ressaltar que, em todos os segmentos de elite rica, a ordem de representação dos quatro grupos é a mesma. Primeiro vem o homem branco, perfazendo sempre quase ou mais que a metade do segmento. Segue-o, de longe, a mulher branca. Em seguida, seguindo a mulher branca um pouco mais de perto, vem o homem negro e, por último, em proporções sempre inferiores a $5 \%$, vem a mulher negra. A associação entre riqueza e poder entre os executivos não apenas segue, como agrava esse padrão. Os homens brancos, que são 63\% dos ricos, chegam a perfazer $77 \%$ desse segmento da elite rica. No outro extremo, as mulheres negras, $4 \%$ dentre os ricos de maneira geral, não chegam a 1\% dos executivos ricos. Os homens negros também sofrem uma queda drástica de representação nesse setor, saindo dos seus $14 \%$ do total dos ricos para menos de $6 \%$ nesse segmento. As mulheres brancas caem dos seus $21 \%$ entre os ricos em geral para $16 \%$ entre os executivos ricos. Veja agora como é o caso dos pequenos empregadores.

Gráfico 6.6: Associação entre riqueza e poder por raça e sexo: pequenos empregadores.

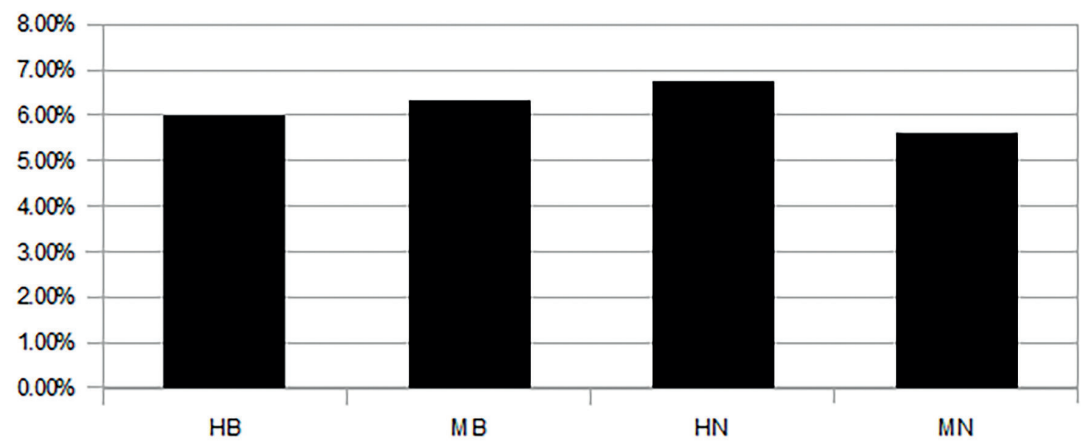

Fonte: IBGE - Censo Demográfico 2010 - Microdados. Elaboração própria. 
A distribuição lembra o que ocorre no caso do segmento estatal pela inversão da desigualdade de gênero entre os dois grupos raciais. Homens negros estão acima das mulheres negras, mas são as mulheres brancas que estão acima dos homens brancos. Contudo, diferentemente do segmento estatal, no qual as mulheres negras encontram uma associação entre riqueza e poder mais forte do que homens e mulheres brancas, estando atrás apenas dos homens negros, as mulheres negras ficam em último lugar. Se a maior associação para os homens negros indica uma permeabilidade ao negro e a maior associação para as mulheres brancas, em comparação aos homens brancos, sugere uma permeabilidade à mulher, a posição da mulher negra contraria essas duas tendências. Note-se também que, nesse caso, as diferenças são bem menores, com todas as barras tendo tamanho muito próximo. Na verdade, o que ocorre nesse segmento é uma leve concentração de homens negros e, ao mesmo tempo, uma leve desconcentração de homens brancos que, sendo 63\% dos ricos em geral, representam uma porção de 61,5\% dos ricos pequenos empregadores. Veja agora o que ocorre com o segmento dos burocratas:

Gráfico 6.7: Associação entre riqueza e poder por raça e sexo: segmento burocrático.

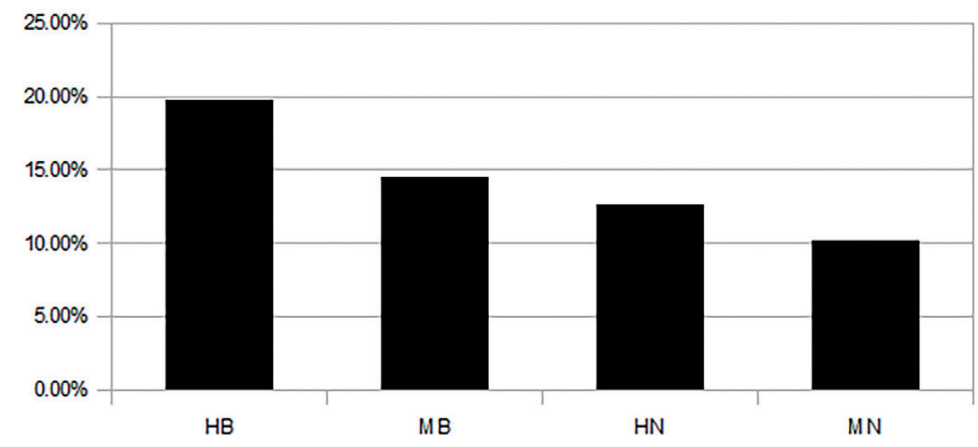

Fonte: IBGE - Censo Demográfico 2010 - Microdados. Elaboração própria.

Observa-se, nesse caso, à semelhança do que ocorre com os executivos, a forma de escada que reproduz a representação dos quatro grupos na elite rica. Não há, contudo, a mesma acentuação do quadro. Como foi visto no segmento dos executivos, não só esse padrão é reproduzido como a intensidade das disparidades 
é intensificada por uma grande impermeabilidade ao homem negro e, mais ainda, à mulher negra. No caso da burocracia, o quadro é mais moderado. Isso difere bastante do que ocorre com a sociedade civil, conforme o Gráfico 5.8, a seguir. Note-se, primeiramente, que, por conta do tamanho ínfimo desse segmento de elite, as probabilidades são muito pequenas. Quanto às disparidades, o que se observa nesse caso é um acirramento drástico da disparidade racial. Homens e mulheres negras que perfazem $16 \%$ dos ricos não representam, em conjunto, 4,5\% desse segmento de elite. A impermeabilidade racial é definitivamente o aspecto mais crítico da associação entre riqueza e poder através da sociedade civil.

Gráfico 6.8: Associação entre riqueza e poder por raça e sexo: sociedade civil.

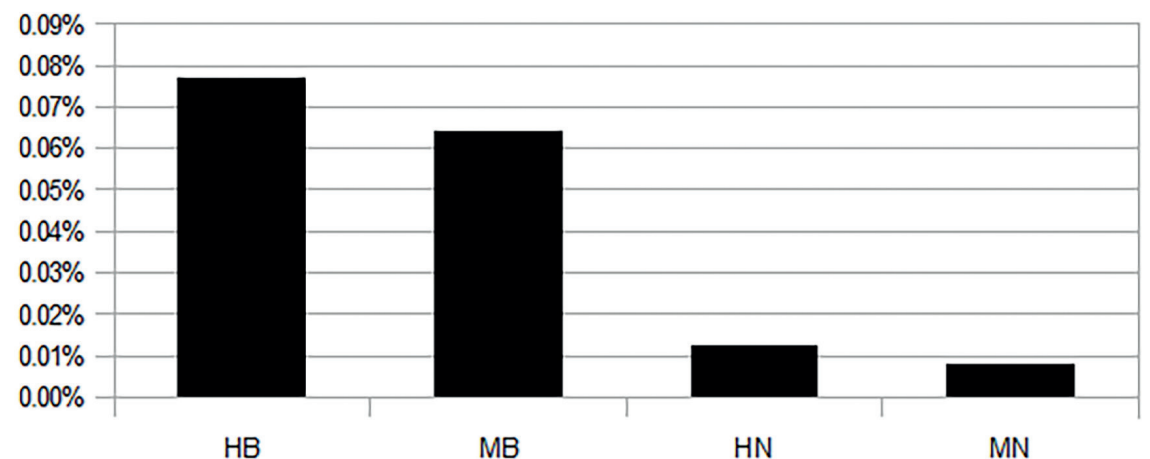

Fonte: IBGE - Censo Demográfico 2010 - Microdados. Elaboração própria.

No panorama geral, o que se observa é que o peso relativo da raça e do gênero sobre a associação entre riqueza e poder varia de acordo com o segmento de elite em questão. É importante ressaltar que os padrões observados não são mera reprodução das diferentes proporções pelas quais os quatro grupos considerados participam da riqueza e dos segmentos de elite. A associação entre riqueza e poder consiste, basicamente, nas variações em torno dessas proporções e da participação dos grupos em cada um dos segmentos de elite. Mesmo os brancos sendo esmagadora maioria entre os ricos e em todos os segmentos de elite rica, observa-se uma concentração de negros ricos em alguns desses segmentos. No caso dos grandes 
empregadores, observa-se uma concentração de homens brancos e negros. Mesmo sendo a proporção de mulheres brancas superior à proporção de negros entre os grandes empregadores, a maior concentração relativa de homens negros indica a existência de mecanismos subjacentes, tornando eminentemente masculino esse segmento de elite. No segmento dos pequenos empregadores, esse quadro se complica, já que, embora exista uma concentração de homens negros, há também uma concentração de mulheres brancas superior à dos homens brancos. É razoável pensar nesse segmento enquanto constituindo, por excelência, uma via permeável a grupos em desvantagem. Contudo, se essa via parece especialmente permeável ao homem negro e à mulher branca, ela permanece fechada à mulher negra.

Com efeito, não importa qual seja o critério de estratificação mais saliente nas diferenças de associação entre riqueza e poder, a mulher negra é o grupo sistematicamente mais prejudicado. A única exceção está no segmento político, onde a associação entre riqueza e poder para as mulheres negras só não é mais forte que aquela que existe para os homens negros. Contudo, as mulheres negras ainda participam com apenas $5 \%$ desse segmento de elite, contra os $4 \%$ de sua participação entre os ricos de maneira geral. Já os homens negros participam com 18\%, contra os seus $12 \%$ na riqueza em geral. As mulheres brancas participam com $26 \%$, contra os seus $22 \%$ na composição do grupo dos ricos. São os homens brancos que caem dos seus 63\% entre os ricos para 54\% de participação no segmento da elite estatal. Sendo assim, a associação favorável entre riqueza e poder para a mulher negra nesse segmento representa um ganho de participação muito discreto. Na verdade, o que parece estar em jogo é uma propriedade do segmento estatal da elite de ser mais permeável à diversidade de uma maneira geral. Com isso, a associação entre riqueza e poder se fortalece para as mulheres negras, mas a participação efetiva que existe no contexto dessa associação não é muito grande. Em geral, mesmo quando determinado segmento parece mais suscetível a constituir uma via de associação entre riqueza e poder para pessoas negras e para mulheres, isso se faz sentir pelo homem negro ou pela mulher branca, mas não pela mulher negra. 


\subsection{Conclusão}

As hipóteses lançadas neste capítulo dizem respeito a como a associação entre riqueza e poder condicional à raça varia em termos de segmentos de elite. Primeiramente, confirmou-se que existe um padrão diferencial de associação entre riqueza e poder segundo à condição racial. Confirmou-se também que esse padrão varia entre os segmentos de elite. Conforme o esperado, o Estado é uma via relativamente mais suscetível à associação entre riqueza e poder para pessoas negras. O mercado, por outro lado, é uma via mais impermeável. Isso se nota em se tratando dos grandes proprietários e, especialmente, dos executivos. A associação entre riqueza e poder é extremamente fraca para os negros em se tratando desse último segmento. Por outro lado, a posição de pequeno empregador se mostra mais permeável, denotando que a associação possível entre riqueza e poder para os negros na esfera econômica está mais circunscrita à posição de pequeno burguês. Refuta-se, por outro lado, a hipótese de que a sociedade civil é um ambiente permeável aos negros. Pelo contrário, esse segmento de elite é aquele para o qual a associação entre riqueza e poder é a mais baixa para pessoas negras. Refutou-se, ainda, a hipótese de que esses diferenciais nos padrões de associação entre riqueza e poder segundo a raça são mediados por desigualdades em termos de áreas especializadas de formação superior.

Finalmente, no que se refere à influência simultânea das condições de raça e de gênero, observou-se que alguns segmentos restringem a associação entre riqueza e poder principalmente para as mulheres, e outros, para as pessoas negras. O segmento dos grandes proprietários é prioritariamente masculino. O segmento dos executivos é prioritariamente branco. O segmento dos pequenos empregadores apresenta uma permeabilidade relativamente maior ao homem negro e, também, à mulher branca, sem que a mulher negra se beneficie dessa tendência à abertura a grupos desfavorecidos. A burocracia também é resistente, sobretudo, à associação entre riqueza e poder para os negros, mas essa resistência é muito menor que aquela existente no segmento dos executivos. O segmento estatal é o único destacadamente favorável 
à associação entre riqueza e poder para as pessoas negras, com homens e mulheres negras contando com associação mais forte que mulheres e homens brancos. Mais ainda, o segmento estatal é o único para o qual a mulher negra não está em último lugar no que se refere à associação entre riqueza e poder. Já a sociedade civil é extremamente impermeável à associação entre riqueza e poder para as pessoas negras, quer se trate de homens, quer se trate de mulheres. As mulheres negras constituem o grupo mais desfavorecido. Para elas, a associação entre riqueza e poder é a mais fraca, mesmo quando um segmento mostra associação mais forte para homens negros, por um lado, ou para mulheres negras, por outro. A única exceção é o segmento estatal. Mas, mesmo nele, as mulheres negras permanecem em desvantagem diante do homem negro. 